\title{
POSSESSÕES DEMONÍACAS E SUAS REPRESENTAÇÕES: O CORPO DA POSSESSA NOS IMPRESSOS INGLESES MODERNOS DO SÉCULO XVII
}

\author{
DEMONIC POSSESSIONS AND THEIR \\ REPRESENTATIONS: THE BODY OF THE POSSESSED IN \\ MODERN ENGLISH PRINTED MATTER OF THE 17th \\ CENTURY
}

Luisa Padua Zanon ${ }^{1}$

Resumo: A modernidade inglesa delineou-se por diversos conflitos religiosos, políticos e sociais. Nesse sentido, o clima de instabilidade e temores somou-se ainda ao reforço da ordem dos Estados Modernos e a um processo de disciplinarização e controle dos corpos. Tal cenário, aliado ao advento da prensa, acentuou a certa vigilância e cuidado para com os corpos femininos e a atuação das mulheres. Em meio a essa apreensão, a esfera do feminino passou a ser cada vez mais associada ao maligno, suscetível ao diabo e à subversão. Assim, a imagem da possessa e do diabo ganham forças e a representação dessa encontra visibilidade na publicação de panfletos e outros textos efêmeros. Considerando isso, o presente trabalho debruça-se sobre esses relatos de possessões demoníacas datados do século XVII, buscando apreender como se deu o processo de construção desses materiais e em que medida eles se articulam com as crenças que assombravam a sociedade nessa Primeira Modernidade.

Palavras-chave: História Moderna; Representação; Possessão; Mulheres; Literatura de rua.

${ }^{1}$ Graduanda em História pela Universidade Federal de Minas Gerais (UFMG). Integrante do grupo de pesquisa "Cultura impressa na Europa Moderna (século XVI-XVIII)". E-mail para contato: luisa.pzanon@gmail.com. Endereço para o Currículo Lattes: http://lattes.cnpq.br/5340085128565242. 
Abstract: Modern England was outlined by several religious, political and social conflicts. In this sense, the climate of instability and fears was added to the strengthening of the order of Modern States and to a process of disciplining and controlling bodies. This scenario, combined with the advent of the press, enhanced the vigilance and care over female bodies and the social behaviors of women. In this apprehension, the sphere of feminine was increasingly associated with the malignant, susceptible to the devil and to subversion. Thus, the image of the possessed and the devil gains strength and their representation found visibility in the publication of pamphlets and other ephemeral texts. Considering this, the present work focuses on these reports of demonic possessions of the 17th century, seeking to apprehend how the construction process of these materials took place and to what extent they were articulated with the beliefs that haunted this Early Modern society.

Keywords: Modern history; Representation; Possession; Women; Street literature

Be angry, and sin not, neither give place to the Devil.

For the Devil is come down having great wrath,

knowing shat his time is but short.

And power was given him to take peace from the earth,

and that they should kill one another. (Revel. 12. 11, \& 6.4 apud The Devils Reign upon Earth, 1655)

Ao longo dos séculos, sobretudo na chamada Idade Moderna, a religião foi um dos agentes catalisadores de diversas mudanças no mundo, imbuindo valores ao imaginário social e movimentando processos de ordenação dos indivíduos. Nesse sentido, os pensamentos em torno do divino e do diabólico rodearam boa parte das produções artísticas, literárias e sociais dos séculos XVI e XVII, recobrindo, assim, a paisagem de diferentes locais. Dentro desse quadro, o presente trabalho debruça-se sobre 
a Inglaterra, localidade na qual as crenças religiosas vão passar por intensas reformulações ao longo da primeira modernidade ${ }^{2}$. Dessa forma, empreende-se aqui um esforço em melhor entender sobre que condições e justificativas foram erigidas e reproduzidas ali as concepções em torno do místico e do sobrenatural.

Somado a isso, há também um interesse em se esclarecer como a imagem do diabo assolou o período abarcado, cristalizando-se na publicação de diferentes relatos que apontavam para a existência de possessões demoníacas. Para tanto, analisa-se aqui um panfleto específico de 1647 intitulado " $A$ strange and true relation of a young woman possest with the Devill, by name Joyce Dovey". Ao relatar um caso de possessão de uma menina, o texto suscita questões a respeito da crença na atuação do diabo e do papel da mulher na trama. Nesse prisma, cabe uma reflexão acerca dos porquês desse cenário e em que medida ele se articula com a dimensão do feminino e a culpabilização e controle sobre as mulheres e seus corpos. Analisando as representações das possessas veiculadas na literatura impressa, tonifica-se aqui a busca pelo entendimento de como esses textos foram construídos e qual a relação deles com os ideários

\footnotetext{
${ }^{2}$ Periodização realizada com base na tradicional divisão historiográfica, na qual interpõe-se uma separação temporal em quatro fases (idade antiga; média; moderna e contemporânea). Nesse prisma, cabe ressaltar que, apesar de serem construções humanas realizadas a posteriori, elas permitem ainda uma delimitação dos eventos ao longo de suas ocorrências, facilitando uma maior compreensão destes. Nesse viés, utiliza-se aqui ainda a ideia de "Primeira Modernidade" - a fim de acentuar as dinâmicas que são colocadas em curso logo no início do período moderno salientando as experiências ali dispostas e dirigindo um outro olhar para as demarcações temporais e culturais já estabelecidas.
} 
circulantes. De igual modo, abre-se um horizonte para a compreensão de como esses materiais contribuíram para o reforço de um arquétipo da mulher ideal e um fortalecimento da dominação masculina, implicando, pois, modificações no que tange aos processos de convivência e sociabilização (BOURDIEU, 2020: 60).

Ao centralizar a análise em torno das produções impressas e textuais que são veiculadas na modernidade, é essencial a delimitação da importância desses objetos enquanto ferramentas no auxílio para a apreensão de realidades históricas. Conforme argumentado por Sharon Achinstein (2001), a construção desses materiais englobava dimensões que perpassam pela sociabilidade, espacialidade e materialidade, aliando-se ainda a um processo dinâmico e multifacetado no qual uma série de agentes e instituições se defrontam. No entanto, é justamente por meio desse encadeamento que se deu a construção das identidades sociais e das relações de dominação entre os indivíduos. Nesse sentido, um conceito chave a ser elencado aqui é o de "representação", na medida em que elas são circuladas dentro desses textos e exprimem valores e modelos sociais vigentes (CHARTIER, 2011). No caso, as representações funcionam como "sistemas de interpretação", responsáveis por reger a relação entre os homens e o seu mundo, "orientando e organizando as condutas e as comunicações sociais" e impactando, concomitantemente, na "assimilação dos conhecimentos e no desenvolvimento individual e coletivo" (JODELET, 1993: 5). Assim, ancoradas em uma dada realidade, elas atribuem significado ao mundo e resultam em formas de saber, atuando 
também na própria construção do imaginário social e intermediando as relações de uma comunidade com a outra.

Por conseguinte, e tendo em mente que as ações colocadas em curso pelos indivíduos se alinham às determinadas conjunturas vigentes de cada momento, sobressai-se aqui a necessidade de se melhor compreender o contexto de produção desses impressos e sobre como tais materiais vão estar sedimentados em torno de uma vida coletiva própria, regida por tensões e conflitos inerentes à modernidade. Trata-se, portanto, de uma Inglaterra que, em meio ao século XVII, encontra-se recém-saída de atritos políticos e religiosos, de tal forma que se vê confrontada com novas experiências religiosas e comportamentais (DELUMEAU, 1989: 141; HILL, 1987: 29; THOMAS, 1991: 19). ${ }^{3}$ Ao mesmo tempo, a localidade perpassa, nesse período, por divergências políticas e por mudanças que reverberam no campo da economia e da sociedade. ${ }^{4}$ Assim, visualiza-se um extenso processo de transformações e instabilidades, no qual o fervor escatológico e a ideia de que o mal estava à solta foram propiciados

${ }^{3}$ Destacamos aqui alguns dos acontecimentos que marcaram os séculos XVI e XVII na Inglaterra, como a Reforma Protestante (com a propagação do Anglicanismo), a ascensão da dinastia Stuart ao poder e a eclosão da Guerra Civil Inglesa.

${ }^{4}$ Acerca desse contexto, delimitam-se ainda as chamadas Guerras Civis Inglesas (1642-1651) - provenientes, sobretudo, de atritos entre o rei e o parlamento -, que culminaram em uma série de batalhas que abalaram significativamente a sociedade inglesa. Por meio dela, verifica-se a disputa entre os chamados Round-heads e os Cavaliers, bem como a instalação de uma crise econômica e política na região, levando, inclusive, à morte do monarca Charles I em 1649 e a implementação de uma breve República. Em consonância, visualiza-se nesse momento abalos expressivos nas relações entre o Estado e a Igreja, bem como entre as relações da Inglaterra com seus países vizinhos. 
(ALMOND, 2014: 168). Nesse sentido, as angústias, ansiedades e temores encontram na figura do diabo a sua personificação, de modo que a crença em um diabo atuante e maléfico que assombrava a sociedade se solidifica e se reproduz nesse mesmo momento (MUCHEMBLED, 2001: 145-147).

Em consonância, se fortalece cada vez mais a ideia do Anticristo e do fim do mundo, fazendo do período supracitado um momento de extremo milenarismo, melancolia e crença no poder do Diabo (CLARK, 1999: 340). Sublinha-se também o peso que a Reforma Protestante teve no que concerne ao processo de interiorização da culpa e dos pecados. Com as alterações religiosas - vide abolição do purgatório, dos santos e dos milagres -, a angústia coletiva e o desespero religioso aumentam, e os indivíduos se veem à mercê do mal (THOMAS, 1991: 453). Não por acaso, verifica-se a individualização de uma luta contra Satã e o mal instalada, sobretudo, na crença de um diabo presente e vívido que habitaria o interior de cada indivíduo. Dessa forma, é propiciado, pois, o surgimento e a propagação de uma forte demonologia voltada para a compreensão da atuação do diabo no mundo. Como um debate em aberto, ela envolvia um esforço científico e intelectual que incidia ainda mais na existência de uma fluidez entre o universo natural e o sobrenatural.

Nessa perspectiva, a mulher - em consonância ao discurso eclesiástico que lhe atribuiu um estatuto de inferioridade frente ao homem será associada ao maligno e, consequentemente, ao diabo. Essa construção, por sua vez, pode ser visualizada desde a Antiguidade e as histórias circulantes na Grécia Clássica, em que, a exemplo de Circe e Medeia, já se 
verifica uma incorporação do maligno e do mágico pela figura da mulher. No entanto, é com a ascensão do Cristianismo que essa visão inferiorizante do feminino ganha força e se difunde de forma expressiva. Assim, tendo o mal e o pecado encarnados em Eva, verifica-se, pois, a disseminação de um "antifeminismo agressivo, especialmente a partir do século XV", bem como o reforço do controle sobre o agir e o pensar da mulher (LIEBEL, 2004: 12). Nesse curso, percebe-se um processo de demonização do feminino, responsável por alocar as mulheres como seres pecadores e subversivos por natureza, suscetíveis ao mal e à ação do diabo.

Equitativamente, tal cenário alia-se ainda a um reforço da ordem e dos controles dos corpos femininos, tidos como corruptos e pecaminosos (AMUSSEN; UNDERDOWN, 2017: 22). Desse modo e, entendendo o corpo como algo inscrito socialmente, pode-se verificar um processo de adestramento e vigilância constante dos corpos e condutas femininas, frente a um contexto de angústias e tensões sociais que se aglutinam justamente na figura da mulher pecaminosa (WOLFF, 2011: 101). Nessa ótica, a mulher é tida como uma ameaça à ordem, à moral e à harmonia social, devendo ser cerceada e restringida. Assim, tem-se, cada vez mais, a fortificação de um discurso misógino que evoca um controle da sexualidade feminina e das ações protagonizadas por mulheres, cerceando e regulamentando o campo de atuação dessas (LIEBEL, 2004: 64).

O mal era encarnado na figura da mulher desviante, de modo que os casos de possessão demoníaca e feitiçaria eram, paulatinamente, associados à esfera do feminino. No caso, a possessão, como um desvio da natureza, 
envolvia a tomada do corpo feminino pelo diabo, de modo que a vítima se sucumbia, involuntariamente, à ação demoníaca (PURKISS, 1998: 243). No entanto, muitos dos relatos apontam para uma associação desse fenômeno a, essencialmente, mulheres e crianças, devido ao ideário de que estas eram seres mais frágeis e inferiores e, portanto, mais suscetíveis ao mal e à tentação (ALMOND, 2004: 22). Ainda nesse quadro, sublinha-se que a possessão envolvia uma série de questões que concernem ao corpo do possesso. Fica perceptível como a identificação da possessão se dava por um conjunto de caraterísticas, gestos e comportamentos corporais que permitiam a recognição de que o diabo estaria agindo sobre aquele indivíduo (USZKALO, 2015: 56). Sendo assim, posturas tidas como “anormais" poderiam ser passíveis de associação com a possessão. A exemplo, cita-se a mudança no timbre de voz, a presença de convulsões, espasmos ou vômitos e a demonstração de maior força ou violência.

Desponta-se daí uma importante dimensão que englobava os processos de acusação e identificação da possessa. Eles eram regidos por uma lógica própria, sendo delineados pela existência de uma condição peculiar e distintiva, que permitia a classificação do ato como uma possessão de fato. De igual forma, as possessões apresentavam-se como negociações que envolviam a vítima, aqueles que identificaram o fenômeno e as testemunhas que o presenciaram (USZKALO, 2015: 10). Nessa ótica, visualiza-se uma série de agentes, e sujeitos se entrecruzam nos processos de possessões, tornando-os complexos e abstrusos. É dentro desse sentido, pois, que se pode compreender a formação e transmissão de ideias a 
respeito do diabo e da conduta feminina. Ou seja, é em cima desse cenário que o medo irá se cristalizar e tomar forma no corpo da possessa, e é a partir de uma nova invenção que esses ideais vão ser repercutidos e veiculados: a prensa.

Como elemento fundamental para a divulgação de notícias, ideias e informações, a publicação de impressos na modernidade coloca-se como um processo delineado por lógicas e condições próprias (CLARK, 2003: 23). A produção de um texto envolvia uma extensa rede de agentes (incluindo autores, editores, revisores, tipógrafos, vendedores e leitores), de modo que a criação e circulação do material exigia um longo e dinâmico processo (CHARTIER, 2014: 46). Recobertos ainda por diferentes escolhas e intenções estilísticas, gráficas e mercadológicas, o texto emergia, portanto, como algo múltiplo, fluido e contextual, marcado sobretudo por disputas de interesses e relações de prestígio, poder e autoridade (HALASZ, 1977: 133).

Nesse viés, destaca-se aqui a produção de textos voltados para um público mais amplo e com um acesso mais fácil. Intituladas de "literatura de rua", essas obras - que incluíam panfletos, baladas e single-sheets ${ }^{5}$, por exemplo - eram caracterizadas por uma produção mais rápida e um linguajar mais simples, contendo um valor mais acessível e uma qualidade inferior (SPUFFORD, 1981: 249). No caso dos panfletos, ainda que considerada a fluidez e dinamicidade que perpassava pela produção desses

5 Textos impressos de caráter efêmero e produção mais rápida e barata. Eram caracterizados por serem feitos de materiais mais frágeis e com um tipo de amarração simplificada e menos prestigiosa (SURH, 2011: 77). 
textos, verifica-se a existência de um conjunto de características próprias no que tange a formato, layout, estilos de letra e tamanho. Em sua maioria, tais publicações eram precedidas, portanto, por certas configurações estilísticas e convenções tipográficas que lhe conferiam uma audiência e um mercado específico. Equitativamente, elas continham uma retórica especial e mecanismos que procuravam conferir veracidade e legitimidade ao que estava sendo exposto (SUHR, 2011: 162). Não por acaso, verifica-se em boa parte dos panfletos da época a menção a testemunhas ou citações de autoridade, assim como a presença de trechos da bíblia e palavras como "true", "faithful" e "trusty" nos títulos e prefácios, a fim de endossar a autenticidade da história veiculada.

À luz dessas considerações, sublinha-se aqui o impresso anteriormente mencionado de autoria de James Dalton ${ }^{6}$. Intitulado $A$ strange and true relation of a young woman possest with the Devill, by name Joyce Dovey, o curto panfleto de 1647 evoca em sua narrativa o relato de uma possessão demoníaca que teria acometido a jovem Joyce Dovey. Disponível na Biblioteca Britânica por meio do banco de dados Early English Modern Books, o impresso é um exemplo dos variados tipos de publicações efêmeras que datam do século XVII na Inglaterra e que foram coletadas e arquivadas. A história, que se passa em Bewdley,

${ }^{6}$ Sobre o autor do panfleto, não foi possível aferir informações acerca de sua identidade. No entanto, sabe-se, conforme consta nas informações do impresso disponibilizadas pela plataforma, que ele foi publicado em Londres por E.P - sendo uma de suas cópias coletada pelo inglês George Thomason em 23 de dezembro no mesmo ano de sua publicação. Sobre o colecionador George Thomason, ver: LIMA, 2013: 102-115. 
próximo a Worcester, narra o episódio de possessão da menina, que teria sido presenciado e identificado por outros indivíduos. A princípio, o excerto aloca-se como uma importante fonte para a compreensão da dimensão material e linguística dos impressos, assim como da veiculação de representações acerca da possessa e do processo de acusação e reconhecimento do fenômeno.

De início, chama-se atenção para a abertura do texto que já afirma a presença do diabo no mundo e do mal à solta na sociedade. Com uma carta de autoridade logo no começo do panfleto - atestando a veracidade do que estava sendo veiculado -, o texto inaugura a sua escrita mencionando a existência de um conflito e a presença de soldados na região. Nessa ótica, sublinha-se aqui o entrelaçamento da obra com o próprio contexto de sua produção. Trata-se, pois, de um período que está no entrecruzo das Guerras Civis Inglesas, de modo que as turbulências das agitações políticas dessa conjuntura se reverberam nos mais diversos âmbitos sociais (PURKISS, 2007: 389). Com isso, verifica-se um cenário de violências e estresses, coincidindo também com um grande fluxo de notícias e impressos (DAVIES; FLETCHER, 2014: 02). Em igual medida, a guerra oportunizou a ascensão de tensões e ansiedades acerca do gênero e da masculinidade, incidindo em questões relativas à autoridade patriarcal e familiar (PURKISS, 2005: 97). Apesar de ser uma produção voltada para a narrativa de um caso de possessão, percebe-se, concomitantemente, uma alusão ao contexto vigente que se transveste nas próprias páginas do panfleto e se amplia nas tensões que o ambiente ali aglutina. Pode-se pensar também no 
caráter político que algumas possessões poderiam assumir, apresentando-se como casos de manifestação contra a ordem ou alguma autoridade (THOMAS, 1991: 388).

Em sequência, a narrativa inicia a abordagem da possessa, mediante a identificação de que o diabo estaria atuando sobre a garota. Ressalta-se, mais uma vez, o caráter classificatório das possessões, dado que elas poderiam ser identificadas e reconhecidas por mais indivíduos mediante um conjunto de características próprias. Em virtude disso, o anormal ganha aqui um caráter especial, pois aquela conduta que agia fora da expectativa ou do esperado, era tida como uma anomalia ou uma subversão, sendo, portanto, negativada. Ao apontar para certo comportamento e colocá-lo como desviante, se glorifica, por outro lado, aquela postura que era prevista para os indivíduos na época. Assim, os panfletos adquiriam um tom e uma função moralizantes, reforçando a ordem e as atitudes esperadas - no caso, as das mulheres - ao passo que repulsava outras.

Tal situação é perceptível no panfleto abordado, dado que a vítima na história é acusada de estar possuída justamente pela rejeição de palavras divinas e sermões. A exemplo, o autor no texto cita:

[...] who after the hearing of a Sermon, seemed to be much wrought upon and dejected, who afterward fell into some passions, and (as was conceived by her friends) Convulsion fits [...] (DALTON, 1647).

$\mathrm{O}$ ato de rechaçar e reprovar tais discursos era tido como algo problemático e subversivo, dado que se tratava de uma sociedade 
extremamente religiosa. Desse modo, a renúncia a elementos e símbolos bíblicos era interpretada como uma anormalidade e um sinal da influência e da atuação do diabo no mundo. Com isso, ao expor tal caso, se reforça, por outro lado, o que era esperado dos indivíduos; isto é, a adoração e o respeito pelas palavras e elementos religiosos.

Por conseguinte, no panfleto mencionado outras características permitem a identificação da possessa. No caso, sublinha-se, a princípio, o papel das testemunhas nesse processo e, conjuntamente, o peso conferido à situação por se tratar de uma mulher. É relatado que a garota teria apresentado episódios de convulsão e espasmos, coincidindo com a presença de uma extrema força e uma expressiva mudança no tom de voz. A exemplo, o autor menciona: “...he makes the woman's tongue and organs instruments of speech, but it is in a bigger and grosser tone then her ordinary speech [...] she fell upon him very violent" (DALTON, 1647). Percebe-se, de antemão, que o ato de a personagem ficar violenta ou falar com uma voz mais grossa, era tido como anormal e, portanto, relacionado a uma atuação do diabo. Isso porque o esperado era que a mulher mantivesse a postura de quieta, calma e permissiva, conforme ditavam os discursos religiosos e sociais da época (LIEBEL, 2004: 23).

Somado a isso, a presença de convulsões e epilepsias atesta para a multiplicidade de causas às quais a possessão poderia ser vinculada. Tais ocorrências mesclam as associações da crença no diabo aos diagnósticos médicos, teológicos e filosóficos provenientes dos tratados demonológicos da época (USZKALO, 2015: 21). À luz disso, a possessão aparece ainda 
como uma justificativa e uma explicação para fenômenos biológicos ou tormentos físicos e mentais que, até então, não encontravam respostas nas explicações científicas. Apesar dessas premissas, cabe pensar que muitas das associações da possessão com as mulheres caíam, na verdade, em discursos pautados na misoginia, associando a possessa à manifestação de histerias, períodos menstruais ou outros transtornos. Nesse prisma, o corpo feminino é, mais uma vez, objeto de atenção e repulsa, inspirando medidas para o seu controle e limitação. Acima disso, destaca-se o modo como esses casos perpassam por uma linguagem corporal e gestual própria, envolvendo também dimensões afetivas e emocionais. Assim, a possessão delimita-se como uma experiência humana atrelada a um contexto específico e às tensões que ali se inserem, podendo ainda estar articulada à melancolia e a sentimentos de raiva ou frustração.

Posto isso, depreende-se que a veiculação de tais relatos, por meio dos impressos, contribuiu para a reprodução de um certo ideário a respeito das possessões demoníacas e da crença na atuação do diabo no mundo. Nesse viés, a análise em torno das representações veiculadas nesses materiais permite entender em que medida elas estavam ancoradas em uma dada realidade e apontam para determinadas condições sociais, políticas e econômicas. Nesse caso, elas se inserem como importantes mecanismos para a melhor compreensão de como se sucedeu a interação entre os indivíduos e a circulação de ideias. Por conseguinte, o estudo em torno desses materiais contribui para ressaltar a fluidez e a complexidade que abrangia a elaboração e a veiculação dos impressos, atestando para a 
existência de disputas e tensões próprias. Ponderar sobre isso auxilia, portanto, em um maior esclarecimento acerca dos tênues limites - sobretudo em uma sociedade regida cada vez mais pelo medo do Diabo - entre a literatura, religião e tradição, nas quais o natural se fundia ao sobrenatural (CAMBERS, 2009: 35).

Em consonância, ao debruçar-se sobre tais relatos verifica-se a reprodução do estigma em torno da figura feminina, ao passo que as mulheres são "condensadas em uma única palavra: desviantes" (LIEBEL, 2020: 25). A possessão demoníaca, associada em grande medida às mulheres, encontra no imaginário coletivo o respaldo da existência da malignidade que habitaria os corpos femininos. Sendo assim, a mulher é, por natureza, má; ela reflete o pecado de Eva em si e apresenta-se como um ser subversivo e inferior se comparado aos homens (GREENBLATT, 2018: 120). Nesse prisma, fazia-se necessário um reforço da ordem e do poder patriarcal, sujeitando as mulheres às instituições sociais, religiosas e familiares, destituindo-as de uma autonomia. De igual forma, a sexualidade e o corpo feminino se veem, cada vez mais, restringidos e cerceados, recobertos pela crença de que eram poluídos e corruptos e que deveriam ser, portanto, controlados.

Por fim, este trabalho também possibilita uma melhor compreensão das relações travadas entre os indivíduos e as instâncias religiosas e políticas, que eram propagadas, sobretudo, pelos impressos. De certo, elucida ainda a própria alocação social da mulher nas sociedades, a qual insurge, por sua vez, em uma condição inferioridade e marginalização. 
Nesse sentido, encadeia-se um processo de dominação masculina, na qual o arquétipo da mulher "ideal" é contraposto ao da "desviante e subversiva". Assim, verifica-se a sobreposição de uma visão masculinista dentro dos discursos e práticas sociais, legitimando e naturalizando as relações desempenhadas entre homens e mulheres no período.

Acima disso, o presente texto revela um esforço historiográfico de melhor entender as condições pelas quais a crença no divino e no diabo foi repercutida nos impressos na Inglaterra, o que por si só reflete em escolhas humanas que partem de contextos específicos. Dito isso, "certezas surgem, certezas se vão; só permanece a história, porque a história muda com os eventos que registra" (HILL, 2012: 334), de modo que ela não só fornece uma leitura de mundo, ao iluminar o passado, como também, no pensamento de Sandra Pesavento (2007), auxilia a preencher vazios.

\section{Referências}

ACHINSTEIN, Sharon. Women on Top in pamphlet literature of the English Revolution. Women's Studies, Northwestern University, v. 24, n. 1-2, p. 131-163, 1994.

ALMOND, Philip. Demonic Possession and Exorcism in Early Modern England: Contemporary Texts and their Cultural Contexts. Cambridge: Cambridge University Press, 2004.

ALMOND, Philip. The Devil: A New Biography. Ithaca: Cornell University Press, 2014.

AMUSSEN, Susan; UNDERDOWN, David. Gender, Culture and Politics in England, 1560-1640. Londres: Bloomsbury Publishing Plc, 2017. 
BOURDIEU, Pierre. A dominação masculina. Tradução de: Maria Helena Kühner. 18. ed. Rio de Janeiro: Bertrand Brasil, 2020.

CAMBERS, Andrew. Demonic Possession, Literacy and "Superstition" in Early Modern English. Past \& Present, n. 202, p. 3-35, 2009.

CHARTIER, Roger. O mundo como representação. Estudos Avançados, v. 11, n. 5, p. 173-191, 1991.

CLARK, Sandra. Women and Crime in the Street Literature of Early Modern England. New York: Palgrave Macmillan, 2003.

CLARK, Stuart. Thinking with demons: Idea of Witchcraft in Early Modern Europe. Oxford: University of Oxford, 1999.

DAVIES, Simon F.; FLETCHER, Puck. Introduction. In: DAVIES, Simon F.; FLETCHER, Puck (Eds.). News in early modern Europe: currents and connections. Boston: Brill Leiden, 2014.

DELUMEAU, Jean. Nascimento e Afirmação da Reforma. São Paulo: Pioneira, 1989.

GREENBLATT, Stephen. Ascensão e Queda de Adão e Eva. Tradução de: Donaldson M. Garschagen. 1. ed. São Paulo: Companhia das Letras, 2018.

HALASZ, Alexandra. The marketplace of print: Pamphlets and the public sphere in Early Modern England. Cambridge: Cambridge University Press, 1977.

HILL, Christopher. O mundo de ponta cabeça. São Paulo: Companhia das Letras, 1987.

HILL, Christopher. O século das revoluções: 1603-1714. São Paulo: Editora Unesp, 2012.

JODELET, Denise. Representações sociais: um domínio em expansão. In: Les représentations sociales. Paris: PUF, 1989. p. 31-61. 
LIEBEL, Silvia. Demonização da Mulher: a construção do discurso misógino no Malleus Maleficarum. 74f. Monografia de especialização (Pesquisa Histórica) - Setor de Ciências Humanas, Letras e Artes, Universidade Federal do Paraná, Curitiba, 2004.

. O mundo às avessas na Europa dos séculos XVI e XVII. 2006. 180 f. Dissertação (Mestrado em História) - Setor de Ciências Humanas, Letras e Artes, Universidade Federal do Paraná, Curitiba, 2006.

LIEBEL, Sílvia; LIEBEL, Vinicius. Mulheres, Gênero e Conservadorismo: uma genealogia da violência e da dominação. Penápolis: Editorial Sociologia, Política e Cidadania, 2020.

LIMA, Veronica. Uma narrativa da Revolução Inglesa por meio de seus impressos: George Thomason e sua Coleção (1640-1660). In: SEMANA DE HISTÓRIA DA UNESP: HISTÓRIA, LEITURA E CULTURA MIDIÁTICA, XIX. Anais.... Franca, 2013. p. 102-115.

MUCHEMBLED, Robert. Uma história do diabo - Séculos XII-XX. Rio de Janeiro: Bom Texto, 2001.

PESAVENTO, Sandra. Sensibilidades: escrita e leitura da alma. In: LANGUE, Frédérique (Org.). Sensibilidades na história: memórias singulares e identidades sociais. Porto Alegre: Editora da UFRGS, 2007.

PURKISS, Diane. Invasions: Prophecy and Bewitchment in the Case of Margaret Muschamp. Tulsa Studies in Women's Literature, v. 17, n. 2, p. 235-253, 1998.

PURKISS, Diane. Literature, Gender and Politics During the English Civil War. Cambridge: Cambridge University Press, 2005.

PURKISS, Diane. The English Civil War: A people's history. Perennial: UK Edition, 2007. 
SPUFFORD, Margaret. Small Books and Pleasant Histories - Popular Fiction and its Readership in Seventeenth-Century England. Cambridge: Cambridge University Press, 1981.

SUHR, Carla. Publishing for the masses - Early Modern English Witchcraft Pamphlets. Société Néophilologique, Mémoires de la Société Néophilologique de Helsinki, Tome LXXXIII. 2011.

THOMAS, Keith. Religião e o declínio da magia. Crenças populares na Inglaterra - Séculos XVI e XVII. São Paulo: Companhia das Letras, 1991.

USZKALO, Kirsten. Bewitched and Bedeviled: A Cognitive Approach to Embodiment in Early English Possession (Cognitive Studies in Literature and Performance). Nova York: Palgrave Macmillan, 2015.

WOLFF, Janet. Recuperando a corporalidade: Feminismo e política do corpo. In: MACEDO, Ana Gabriela; RAYNER, Francesca (Orgs.). Gênero, Cultura visual e performance: Antologia Crítica. Ed. Húmus, 2011. p. 101-120.

\section{Fontes}

Anônimo. The Devils Reign upon Earth. Being a relation of several murtners lately committed, especially that of Sir. Geo Sands his son upon his own Brother. Coleção Thomason Tracts. Biblioteca Britânica: Londres, 1655. Código: E.1646.(4.). Disponível em: $<$ https://0-data-historicaltexts-jisc-ac-uk.catalogue.wellcomelibrary.org/vie w?pubId=eebo-99867992e\&offset=60\&terms=E.1646.(4.)\&size=120>. Acesso em: 04 fev. 2021.

DALTON, James. A strange and true relation of a young woman possest with the Devill, by name Joyce Dovey. Early English Books Online. Biblioteca Britânica: Londres, 1647. Código: D142 (Wing). Disponível em: $<$ https://0-data-historicaltexts-jisc-ac-uk.catalogue.wellcomelibrary.org/vie 
Cadernos de Clio, Curitiba, v. 11, $n^{\circ} .1,2020$

w?pubId=eebo-ocm 12233809 e\&terms $=\mathrm{A} \% 20$ strange $\% 20$ and $\% 20$ true $\% 20 \mathrm{r}$ elation\%20of\%20a\%20Young\%20Woman>. Acesso em: 04 fev. 2021.

Recebido em: 08/02/2021 Aceito em: 20/04/2021 